\title{
Rational Design of Peptide-Based Inhibitors Disrupting Protein-Protein Interactions
}

\author{
Xuefei Wang ${ }^{1}$, Duan $\mathrm{Ni}^{2}$, Yaqin $\mathrm{Liu}^{3 *}$ and Shaoyong $\mathrm{Lu}^{1,3 *}$ \\ ${ }^{1}$ State Key Laboratory of Oncogenes and Related Genes, Shanghai Jiao-Tong University School of Medicine, Shanghai, \\ China, ${ }^{2}$ The Charles Perkins Centre, The University of Sydney, Sydney, NSW, Australia, ${ }^{3}$ Medicinal Bioinformatics Center, \\ Shanghai Jiao-Tong University School of Medicine, Shanghai, China
}

Protein-protein interactions (PPIs) are well-established as a class of promising drug targets for their implications in a wide range of biological processes. However, drug development toward PPIs is inevitably hampered by their flat and wide interfaces, which generally lack suitable pockets for ligand binding, rendering most PPI systems "undruggable." Here, we summarized drug design strategies for developing peptide-based PPI inhibitors. Importantly, several quintessential examples toward well-established PPI targets such as Bcl-2 family members, p53-MDM2, as well as APC-Asef are presented to illustrate the detailed schemes for peptide-based PPI inhibitor development and optimizations. This review supplies a comprehensive overview of recent progresses in drug discovery targeting PPIs through peptides or peptidomimetics, and will shed light on future therapeutic agent development toward the historically "intractable" PPI systems.

Keywords: protein-protein interaction, undruggable, peptide, peptidomimetics, drug discovery

\section{INTRODUCTION}

Protein-protein interactions (PPIs) play a fundamental role in all life events and cellular activities, regulating cells' lives and death, as well as mediating various biochemical reactions like signal transduction and metabolisms (Li et al., 2020; Luck et al., 2020; Thanasomboon et al., 2020). Thus, PPIs are regarded as the "holy grail" of modern life science and medicine, and they have emerged as a class of promising therapeutic targets toward a plethora of medical conditions (Cunningham et al., 2017; Davenport et al., 2020). PPIs can make up a large-scale and complicated network termed as "interactome" (Koh et al., 2012). Current studies estimated that human interactome consists of about 650,000 PPIs, which represents a fruitful repertoire of drug targets for therapeutics discovery (Vidal et al., 2011). Modulating PPIs is of critical significance in both basic research and clinical translations. It not only facilitates our better understanding to a wide range of biological events, but also constitutes the theoretical basis for current therapeutic agents development. In the era of modern pharmacology, rational design of PPI inhibitor is considered to be a prospective direction for drug discovery, and possess enormous potentials.

Historically, PPIs have attracted extensive attentions in their related researches (Tsai et al., 2009; Milroy et al., 2014; Devkota and Wuchty, 2020). Enormous efforts invested on this topic have retrieved a plethora of high quality PPI system crystal structures, based on which some success has been accomplished in the PPI inhibitor drug design (Schmidt et al., 2014; Sledz and Caflisch, 2018). Nevertheless, due to the by nature biophysical and biochemical limitations, drug 
discovery targeting PPIs still remains a tough task in both academia and industry. One of the utmost difficulties for PPI inhibitor development is the large, shallow and featureless PPI interfaces. Such poor surface architecture poses considerable difficulty for ligand binding, as well as confers great challenges toward the design and optimizations of drug molecules $(\mathrm{Ni}$ et al., 2019). Previous crystallography and modeling studies have unveiled that, in stark contrast to the small molecule binding site, which is relatively deep and covers only 300-500 $\AA^{2}$ area, protein binding interface is generally wide and flat, and its surface area ranges approximately between 1,000-2,000 $\AA^{2}$ (Lo Conte et al., 1999; Ran and Gestwicki, 2018). Consequently, given the difficult topologies of PPI systems, they are commonly deemed as "undruggable," with limited specific inhibitors directing to them identified. However, the recent proposal of "hot spot" notion has greatly promoted the development of PPI inhibitors (Bogan and Thorn, 1998). It provides a tempting alternative for designing orthosteric ligands to directly target the interaction interface, especially for developing motif-based peptide inhibitors, which mimic the important secondary structure, i.e., the "hot spots" along the PPI interface and disrupt its formation.

The last decade has witnessed remarkable advances in handling challenging PPI targets with small molecules (Ji et al., 2017; Chen et al., 2018). Notably, venetoclax (Souers et al., 2013), which is considered as the first FDA-approved BH3-mimetic drug to interfere with PPI, is a ground-breaking milestone of fragment-based drug discovery (Deeks, 2016). With regard to the development of peptides into drugs, unlike small molecules, they mildly occupy a relatively small portion $(\sim 2 \%)$ of the global drug market (Di, 2015). In general, peptide inhibitors support to address some disease targets, which are difficult to be treated with small molecules. Approximately more than 30 peptide drugs were approved during the last two decades (Lee et al., 2019).

Although small molecules dominate the field of drug market so far, peptide inhibitors still represent a class of promising candidates because of their similarity to endogenous ligand, high affinity, and low toxicity. Therapeutic peptides have been validated that they can effectively and selectively inhibit PPIs both in cancer and virus (Lau and Dunn, 2018). On the other hand, drugging PPI targets with peptides or peptidebased inhibitors is also facing various challenges. They are frequently hampered from progressing into clinic owing to their low membrane permeability, poor oral bioavailability and short half-lives after administration (Di, 2015). Additionally, how to achieve higher affinity and better synthesis diversity are also long-held conundrums for peptide-related drug molecule rational design. Rapid advances in medicinal chemistry and chemical biology have proposed a panel of promising resolutions to tackles these issues, including cyclic peptides, hydrogen bond surrogate, and stapled peptides, which can optimize the ADME (Absorption, Distribution, Metabolism, and Excretion) properties of the peptide-based compounds (Sohrabi et al., 2020). Furthermore, strategies such as introduction of rigid backbone linkers and addition of unnatural side chains or modified moiety can also help to enhance ligand affinity and chemical diversity, contributing improved druggability (Klein et al., 2014; Stevenazzi et al., 2014). Notably, these fast-progressing techniques have already obtained reasonable success in an increasing number of critical targets, such as Bcl-2 family members, p53-MDM2, as well as APC-Asef, exhibiting great prospects for future PPI drug discovery and optimizations.

Here, our review first outlines the key characteristics of PPIs and summarizes advanced peptide-based drug candidates. We aim to provide more inspiring insights that will hopefully enhance future PPI drug development. We initially introduce the basic features of proteins binding interface and subsequently give a summary of current methods for designing PPI inhibitors. Importantly, we focus on several successful examples of popular targets to illustrate the feasibility of these modulator design strategies in regulating PPIs. Such cases are holding promise to improve our understanding toward the sophisticated PPI system and aid to accelerate future development of peptide-based PPI inhibitors.

\section{CHARACTERISTICS OF PPI SYSTEMS}

There are a large number of PPI complexes in every organism, some of which turn out to be permanently bound, while others are transient and bind or dissociate under different conditions, subject to changes in temperature and $\mathrm{pH}$, etc. In addition to their overall dynamic nature, PPI interfaces also exhibit different biochemical and biophysical properties relative to the small molecule compound binding pockets. Such unique characteristics of PPI complexes and their interfaces confer differential challenges for their modulation, and distinct therapeutics development strategies have thus been proposed accordingly. In this section, we briefly discuss the structural and biological features of PPI interfaces, which underlie the mechanistic basis for drug discovery targeting PPI systems.

\section{Structural Properties of PPI Interface}

Analysis of the 3D structures of PPI complexes indicates that their interfaces are relatively large and shallow, falling within the range of $1,000-2,000 \AA^{2}$, compared to the ones for typical small molecule binding sites for around 300-500 $\AA^{2}$. Among them, a "standard size" PPI interface is estimated to be about 1,600 $\AA^{2}$ and composed of around 52 amino acid residues (Lo Conte et al., 1999). Historically, PPIs were deemed as "intractable" with their large and flat binding surfaces being smooth and lacking well-defined binding pockets. Furthermore, the high affinity and tight interactions between PPI partners also posed great challenge for ligands to compete for binding orthosterically, hampering the design of PPI inhibitors. Nevertheless, the ever-developing structural analyses have contributed to the emergence of the concept-"hot spots," which has considerably challenged the primitive notion that PPIs are "undruggable" (Bogan and Thorn, 1998). Along the PPI interface, if a residue mutated to alanine with the PPI binding energy differing for more than $2 \mathrm{kcal} / \mathrm{mol}$, it is defined as a hot spot. The area of hot spots are considered to be only about $600 \AA^{2}$ (Lo Conte et al., 1999). It is validated that hot spots residues mainly distribute in the center of the PPI interface, and they frequently consist of Trp, Tyr, and Arg (Halperin et al., 2004). The existence of hot spot residues has thus shed light on 
PPI inhibitors development as it supplies a more specific and well-defined drug target instead of the broad and wide protein interaction surfaces. Through interfering with the hot spot residues within a relatively local region, inhibitor molecules could readily avoid competing with the high affinity protein binding effector while easily disrupting the overall PPI complexes and exerting therapeutic effects. Hence, in summary, understanding PPI structures, especially the corresponding hot spot residues are of vital significance to PPI drug design. So far, targeting PPI hotspots has achieved reasonable success in PPI drug discovery (Zerbe et al., 2012; Akram et al., 2014). In general, medicinal chemists would first focus on the proteins binding interfaces obtained through crystallography studies. Through exhaustive alanine mutagenesis screening or computational analyses (Lao et al., 2014), hotspot residues could be identified and next aid to instruct structure-based inhibitor design. To mimic hotspots' structural effects implicated in PPI processes, various compound candidates are subsequently screened and rationally modified. Through conformational investigations and structure activity relationship analyses and other pharmacological refinements, the potency of the hotspot-based inhibitors can be further optimized, marking the success of the hit-to-lead optimization workflow. Following such scheme, researchers have managed to design a myriad of PPI inhibitors toward a plethora of historically intractable targets including the immune responsesrelated CD2-CD58 (Liu et al., 2005) and PD-1-PD-L1 (Lim et al., 2019; Yang and $\mathrm{Hu}, 2019$ ), inflammation-related TLR4MD2 (Liu et al., 2011) and apoptosis-related Mcl-1-Bim (Denis et al., 2020). Their success depicts the importance of PPI hotspot elucidation and the downstream structure-guided PPI inhibitor discovery.

\section{Biochemical Properties of PPI Interface}

In addition to the structural features, biochemical properties of PPI systems such as their complementarity and hydrophobicity are also critical factors to consider in designing PPI inhibitors (Chene, 2006; Isvoran et al., 2013). In a PPI complex, complementarity is defined as a particular condition that involves the matching of the surface residues from the corresponding interaction partners. Interfaces with less complementarity possess weaker binding force and therefore can be more readily disrupted by inhibitor molecules. From previous studies, it was demonstrated that the complementarity of both homodimer and permanent complex is considerably stronger than that of heterocomplex and non-permanent complex (Xiao and Konermann, 2015). On the other hand, the hydrophobic degree is mainly characterized by the amount of water molecules on the interface. Retrospective studies manifested that the proteinprotein interface is predominantly occupied by $56 \%$ non-polar groups, $29 \%$ polar groups, and $15 \%$ charged groups, respectively (Chene, 2006). It also shows the trend that aromatic residues and hydrophobic residues have higher propensities for interfaces, while hydrophilic residues are more preferred in the buried portions. Thus, it is conceivable that hydrophobicity, polarity and other chemical properties of inhibitors are critical factors to consider for their binding and targeting.

\section{DRUG DESIGN METHODS OF PEPTIDE-BASED PPI INHIBITORS}

PPI inhibitors can mainly be classified into three directions, i.e., small synthetic molecule inhibitors, peptide inhibitors and peptidomimetics inhibitors. By nature, small molecules frequently suffer from undesirable selectivity, resulting in offtarget side effects (Lin et al., 2019), whereas peptides commonly exhibit affordable synthesis availability and more favorable specificity for their targets. Most noteworthy is the additional chemical modifications for synthetic peptides, which are typically designed to mimic key structural domains in the natural PPI partners. Peptide-based inhibitors, with increased bioavailability and improved permeability, have been gaining prominence in the field of PPI drug design.

Here, we discuss the advanced strategies for the development of peptide-based inhibitors in terms of peptides and peptidomimetics.

\section{Design Method for Peptide Inhibitors}

The conventional method of designing peptide inhibitors is to introduce tailored oligopeptides that are modified based on several important residues along the original PPI interfaces (e.g., hot spots) to inhibit proteins binding (Schatti et al., 2017). It is worth noting that the design of peptide inhibitors efforts have made impressive progress over the past years (Scott et al., 2016). Ya-Qiu Long and colleagues designed a series of short peptides (7-17 residues) comprising key amino acid residues which are critical for integrase (IN) catalytic activities or viral replication (Li et al., 2006). They presented a novel "sequence walk" strategy covering the whole 288 residues of IN in an attempt to unravel the "hot spots" of PPI on IN. Two novel peptides NL-6 and NL-9 were then identified with IC $_{50}$ values of 2.7 and $56 \mu \mathrm{M}$ for strand transfer activity. In addition, Mingjie Zhang group has discovered a potent and specific GABARAPselective peptide targeting Atg8-AnkG to inhibit autophagy ( $\mathrm{Li}$ et al., 2018). The highly effective inhibitory peptide derived from $270 / 480 \mathrm{kDa}$ ankyrin-G binds to GABARAP with $K d \approx$ $2.6 \mathrm{nM}$. Although some researchers have successfully developed several peptide inhibitors, the pharmacokinetic properties of peptides still substantially suffer from major drawbacks such as poor cellular permeability and high metabolic instability. These issues considerably limit their further optimizations and clinical applications.

\section{Design Method for Peptidomimetic Inhibitors}

Peptidomimetics are defined as peptide-like molecules that encompass amino acid analogs and other chemical moieties with specific pharmacophores (Vagner et al., 2008; Lenci and Trabocchi, 2020). They are designed to mimic the 3D structures of the original PPI binding partners or segments and further compete with them for PPI disruption. Peptidomimetics usually mimic specific PPI interfacial structures such as $\alpha$ - helixes or $\beta$-sheets (Wendt et al., 2021), and the addition of functional modifications toward the lead peptide templates can enormously enhance their potency and efficacy. Relative to natural peptides, 


\section{Cyclization reactions}

\section{Backbone modifications}

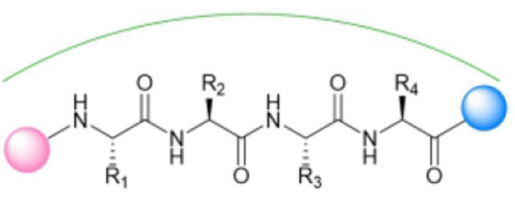

Head-to-tail

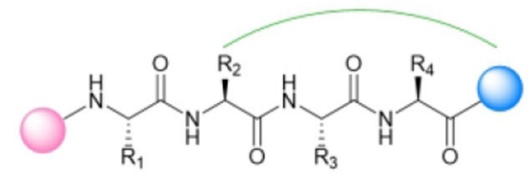

Sidechain-to-tail

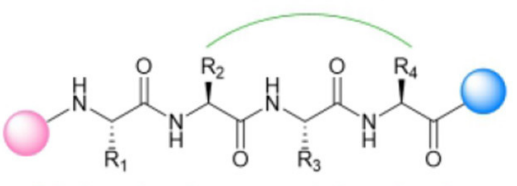

\section{Sidechain-to-sidechain}<smiles>[R3]C(NC(=O)C([R3])Nc1ccco1)C(=O)NC([R3])C(=O)NC([R])C(=O)c1ccco1</smiles>

Backbone-to-backbone

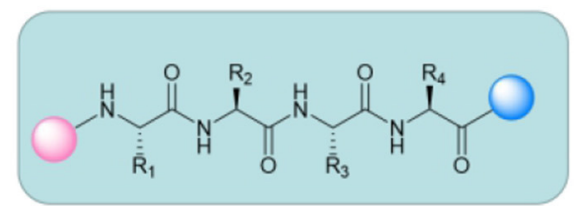

\section{Peptide template}

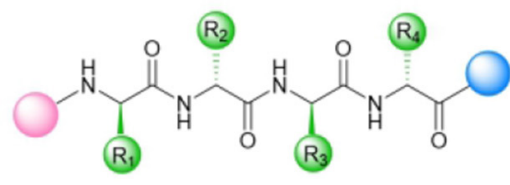

D-peptides

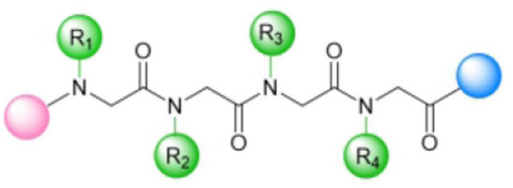

Peptoids<smiles>[R]C(C)NC([R])CC(=O)NC([R8])CC(=O)NC([R8])CC(=O)c1ccccc1</smiles>
$\beta$-peptides

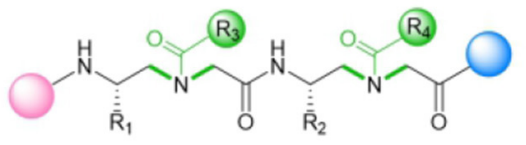

$\gamma$-AApeptides

FIGURE 1 | Current representative mainstream strategies for peptidomimetic PPI inhibitors design and optimization.

introduction of medicinal chemical functional groups or artificial pharmacological structures can substantially enhance their inhibitory activity as well as bypass the intrinsic limitations such as poor proteolysis stability or compromised bioavailability (Qvit et al., 2017). Hence, they are considered as one of the state-ofthe-art trends in the field of PPI inhibitor drug development. The design of peptidomimetic inhibitors is frequently classified as the category of structure-based drug design (SBDD) (Pelay-Gimeno et al., 2015). Typically, it starts with selecting key residues within the PPI systems as templates, such as identification of the hotspot residues. Next, through rational modifications, the initial template structures are optimized to ensure that the segments devised are able to compete and fill the space occupied by the originally recognized PPI peptide chains (Shin et al., 2017). Finally, the modified peptide molecules are assessed for pharmacological activity and may undergo further optimizations. Peptidomimetics design is currently regarded as an eminently practical and promising approach for discovering peptide-based PPI inhibitors. So far, they have achieved fruitful success in taming series of critical but intractable PPI targets such as the MLL1-WDR5 (Karatas et al., 2013), APC-Asef (Jiang et al., 2017; He et al., 2021), DCN1-UBC12 (Zhou et al., 2018), and APP-Mint2 (Bartling et al., 2021). Some of them have even marched into clinical applications. For example, Nelfinavir, which was launched into the market in 1997 for the treatment of human immunodeficiency virus (HIV) infectious diseases, was contrived by the aforementioned strategy, exemplifying the power and potential of peptidomimetics-based PPI drug discovery (Wlodawer, 2002).

\section{Chemical Modifying Approaches for Peptide-Based Inhibitor Optimization}

Improving the stability of the active conformation and reducing its high sensitivity toward proteolysis are among the key challenges when performing peptide-based inhibitor development and modifications. Cyclization and backbone alteration are emerging as two supreme strategies to counteract these problems (Wojcik and Berlicki, 2016) (Figure 1).

The fundamental essence of cyclization is to introduce a rigid structure to augment steric constraints through stabilizing the turns, spirals, and extended conformations within the peptide scaffolds. Various strategies such as hydrogen-bonded substitutes, stapling and hairpins are specifically exploited for such purposes. Understanding and improving peptide-based molecules function through conformational restriction has a long history. Stapling, which means intramolecular side-chain-toside-chain crosslinking, is proven to be a useful tool to produce 
peptides with optimized properties (Quartararo et al., 2012). While the $\beta$-hairpin motif containing a D-Pro-L-Pro dipeptide template, is also commonly considered as a basic scaffold for PPI inhibitor development (Robinson, 2008). Interestingly, free rotation for molecules with biological activity are available to be restricted by attaching steric effects, introducing disulfide bonds and utilizing chelation of metal ions (Chen et al., 2001). It becomes clear that peptides with rigid conformation retain reduced flexibility, but enhanced selectivity and less toxicity. Bradley L. Pentelute group presented a novel and subtle method for the perfluoroaryl-cysteine SNAr chemistry toward synthesizing macrocyclic peptides via $\mathrm{N}$-arylation (Lautrette et al., 2016). Through such approach, they retrieved a potent peptide inhibitor targeting the p53-MDM2 interaction with enhanced proteolytic stability and cell permeability (Touti et al., 2019). With continuous development, researchers also managed to utilize similar approach to develop other macrocyclic low-nanomolar p53-MDM2 interaction inhibitors based on the $i, i+4$ macrocyclization scheme, which endowed improved membrane penetrating ability and cytotoxicity toward cancer cells, thereby exhibiting more favorable anti-cancer therapeutic efficacy.

Another prevalent trend in peptide-based PPI inhibitor discovery is rational modification based on the structure of peptide backbone. Along such stream, the original peptide chain and the effective functional groups of great importance to the binding site are generally retained, while some relatively unimportant side chain moieties will be subject to rational modifications. This strategy for peptide refinement mostly focuses on alterations in the main chain including introducing D-peptides, $\beta$-peptides and peptoids (Lee et al., 2019). Primarily, changing stereochemistry by inserting D-amino acids has emerged as a promising methodology for designing peptides inhibitors. They are more resistant against proteolytic degradation than their L-enantiomeric counterparts (de la Fuente-Nunez et al., 2015). Because L-peptides are usually more easily selected by the chiral proteases and quickly cleaved into corresponding amino acid substituents in blood plasma. Such approach can readily prevent the inhibitor molecules from rapid proteolytic degradation. Seetharama D. Jois and co-workers introduced the changes in the chirality of amino acids in the leading compound to improve metabolic stability (Pallerla et al., 2018). As a result, they successfully designed and synthesized a peptidomimetic containing a cyclic and D-amino acid with a nanomolar level $\mathrm{IC}_{50}$ targeting the PPI between HER2 and HER3. Furthermore, adding unnatural amino acids in the main chain to extend the original peptide backbone or replacing peptide bonds with bioelectronic isosteres are also important alternatives to improve the bio-stability of the peptide PPI inhibitors (Choudhary and Raines, 2011). For instance, Aleksandra Misicka and co-workers reported a unique approach that introducing 1,4-disubstituted 1,2,3-triazole rings as peptide bond isosteres to inhibit interaction between NRP-1 and VEGF (Fedorczyk et al., 2019). They managed to modify the "linker" part and the "arm" part of the peptidomimetics to obtain the structural variation. Eventually, the optimized compound Lys (Har)-Gly $\Psi[\operatorname{Trl}]$ Gly $\Psi[\operatorname{Trl}]$ Arg showed outstanding resistance

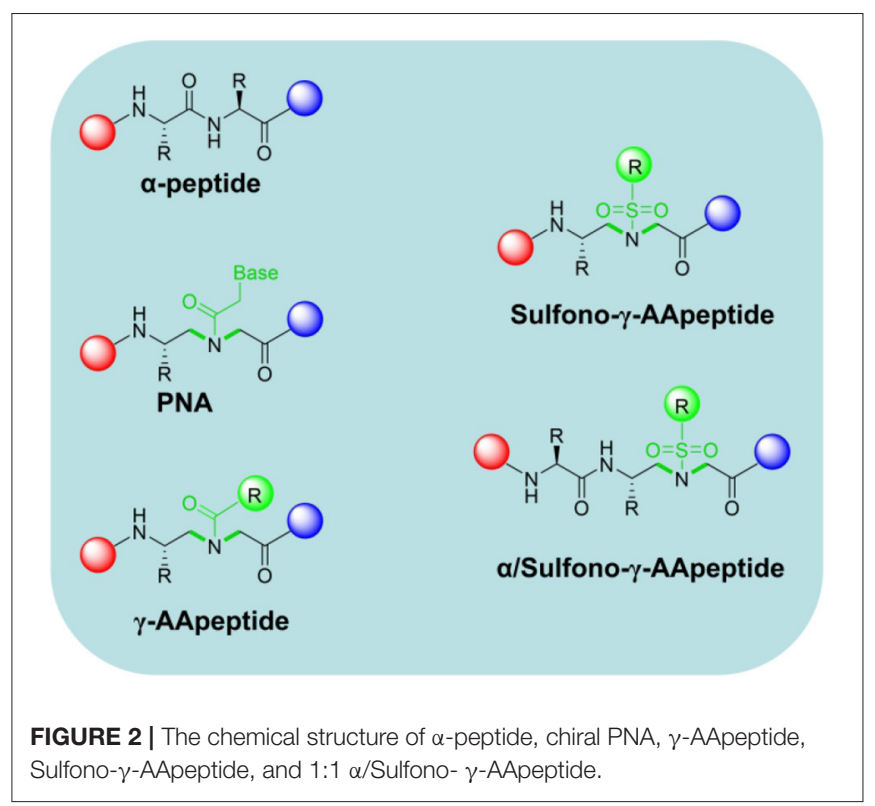

toward proteolysis in human plasma as well as displaying favorable $\mathrm{IC}_{50}$ value of $8.39 \mu \mathrm{M}$.

In addition to the above classical modification methods for sequence-specific peptidomimetics, $\gamma$-AApeptides, as an emerging unnatural peptide backbone, have also gradually entered the field of drug leads design directing to PPIs in recent years. It provides more possibilities for the development of peptide-based inhibitors bearing new scaffolds in the exploration of therapeutic agents toward PPIs.

$\gamma$-AApeptides are constructed based on the chiral peptide nucleic acids (PNAs) backbone (Winssinger et al., 2004; Niu et al., 2011). They are termed as $\gamma$-AApeptides since they are oligomers of $\gamma$-substituted- $N$-acylated- $N$-aminoethyl amino acids (Figure 2). This series of peptidomimetics are easily carried out on the solid phase. $\gamma$-AApeptides can enhance the backbone chemical diversity because half of their side chains could be substituted through the reaction of enormous agents with the secondary amines in the main chain. Both sulfono$\gamma$-AApeptides and 1:1 $\alpha /$ sulfono- $\gamma$-AApeptides are investigated for their folding propensity by X-ray, CD, and 2D NMR (Shi et al., 2016; Teng et al., 2016; Nimmagadda et al., 2019). It is supported by $2 \mathrm{D}$ NMR analysis that these sequences adopt a helical conformation similar to the $\alpha$-helix in the solution, and form a myriad of intramolecular hydrogen bonds. Particularly, sulfonyl groups contribute to form more hydrogen bonding, which facilitate the $\alpha$-helical formation and further stabilize the secondary structure. Cai Group reported a series of unnatural helical sulfono- $\gamma$-AApeptides to mimic the conventional $\alpha$ helix structure, which can effectively and specifically inhibit $\beta$-catenin/BCL9 PPI (Sang et al., 2019). They selected the key residues of BCL9 helical domain as the starting point for the development of novel molecular framework, including Arg359, Leu363, Leu366, Ile369, and Leu373. Compared with native BCL9, the foldameric peptidomimetics showed excellent 
resistance to proteolytic degradation. Furthermore, cellular activity studies manifested that the sulfono- $\gamma$-AApeptides are available to penetrate $\mathrm{Wnt} / \beta$-catenin-dependent cancer cells. These efforts represent a successful application for a new class of helical sulfono- $\gamma$-AApeptides in PPI therapeutics.

Herein, we focus on the drug design approach of peptidomimetics and our substantial efforts were to analyze the successful examples reported in the latest literature, hoping that they could contribute a comprehensive overview of peptide-based drug studies.

\section{EXAMPLES OF PEPTIDE-BASED PPI INHIBITORS}

\section{Inhibitors of Bcl-2 Family PPIs}

The Bcl-2 protein family is involved in the regulation of cell apoptosis essentially by their members' direct binding interactions that control mitochondrial outer membrane permeabilization (MOMP) (Adams and Cory, 2018; Kale et al., 2018). The Bcl-2 family can be divided into two categories, some proteins promoting cell death like Bax and Bak, while others inhibiting programmed cell death, such as Bcl-xL, Bcl-2, Bcl-w, Mcl-1, and Bfl-1. Bcl-2 family proteins share four homology regions designated the $\mathrm{Bcl}-2$ homology $(\mathrm{BH})$ domains, i.e., $\mathrm{BH} 1$, BH2, BH3, and BH4 (Chittenden, 2002; Ashkenazi et al., 2017). Importantly, $\mathrm{BH} 1$ and $\mathrm{BH} 2$ domains are important regions of death-inhibiting proteins with anti-apoptotic activity and heterodimerization. In stark contrast, the $\mathrm{BH} 3$ domain, which exists in all proteins in the Bcl-2 family, is crucial to promote apoptosis (Knight et al., 2019).

The $\mathrm{BH} 3$ domain constitutes the structural basis for two mainstream peptide inhibitor design methods toward the Bcl2 protein family. One is developing small molecule inhibitors mimicking the key $\mathrm{BH} 3$ hotspot residues thereby disrupting the related PPIs (Kotschy et al., 2016), while the other is structural modifications based on the $\mathrm{BH} 3$ peptide scaffold to retrieve peptide-based PPI inhibitors with improved pharmacological properties (Ryan and Davids, 2019).

One of the classic examples of BH3-based PPI inhibitor is its application in Bcl-xL-Bak PPI system. Based on X-ray crystallography and NMR spectroscopy study, it was shown that Bcl-xL encompasses two central hydrophobic $\alpha$ helices surrounded by five amphipathic helices (Sattler et al., 1997).

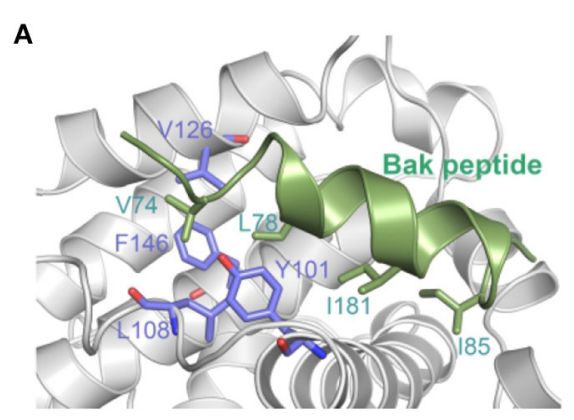

C

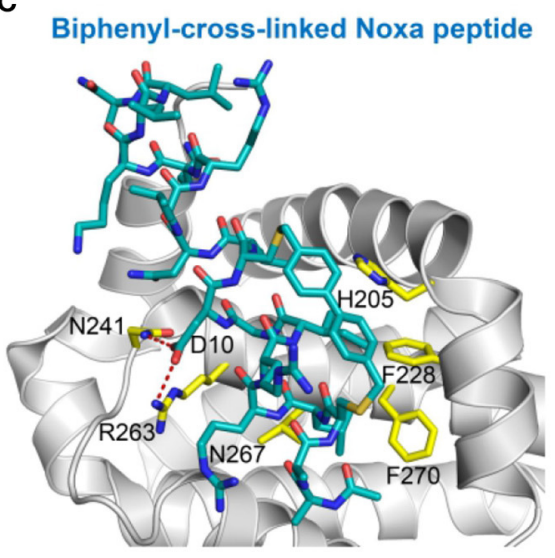

B

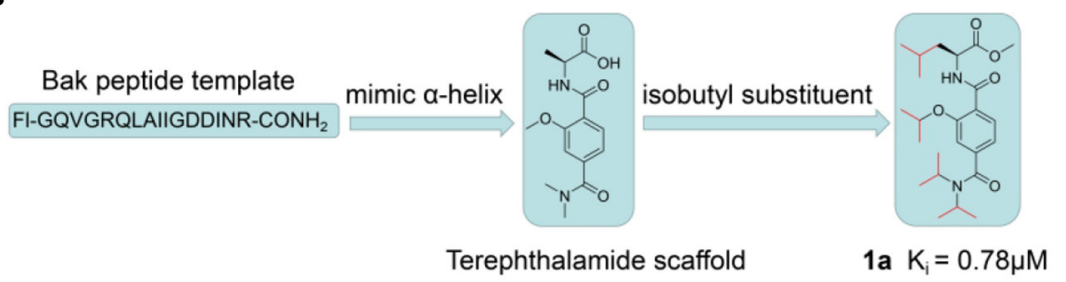

D

Peptide template

Noxa AAQLRRIGDKVNLRQKLLN

$i, i+7$ positions stapling

1b AAC'LRRIGDc"KVNLRQKLLN

$N$-methylation Ala substitution

1c

$A_{m} A_{m} c^{\prime} L R A I G D c " V N L A Q A L L N$

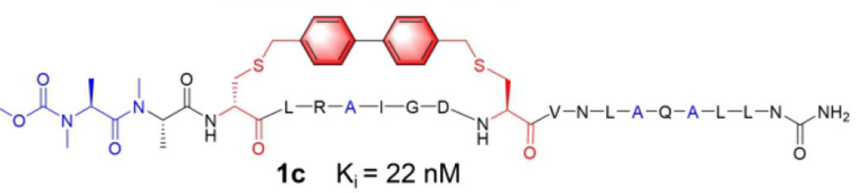

FIGURE 3 | Peptide-based PPI inhibitors targeting Bcl-2 Family PPIs. (A) Structural overview of the Bcl-xl/Bak peptide PPI complex (PDB ID: 1bxl). Bcl-xl and Bak are shown in gray and green, respectively. Hydrophobic residues along the PPI interface are highlighted in purple (Bcl-xl) and green (Bak peptide) stick correspondingly. (B) Development scheme of Terephthalamide derivatives as BH3 mimetics peptide PPI inhibitors. (C) Binding interactions between Biphenyl-cross-linked Noxa peptide (blue carbon atoms) and $\mathrm{Mcl}-1$ (gray carbon atoms). The key residues of side chains in $\mathrm{Mcl}-1$ are labeled in yellow. The red dashed lines represent the hydrogen bonds between Biphenyl-cross-linked Noxa peptide and Mcl-1. (D) Development scheme of Noxa stapled peptides as Mcl-1 inhibitors. 
Further solution NMR experiments revealed that during the $\mathrm{Bcl}-\mathrm{xL}-\mathrm{Bak}$ interaction, Bak binds into a hydrophobic groove on the surface of Bcl-xL using an amphipathic $\alpha$-helix which consists of hydrophobic side chains including the Val74, Leu78, Ile81, and Ile85 residues (Figure 3A). The structure of Bcl$\mathrm{xL}$ in complexed with Bak peptide containing 16 residues derived from the $\mathrm{BH} 3$ region elucidated that this 16-amino acid peptide could be a promising starting point for inhibitor design. Synthetic scaffolds with structural characteristics of the $\mathrm{BH} 3$ helix region is proven to be a prospective strategy for developing Bcl-xL-Bak PPI inhibitors. $\alpha$-Helix mimics derived from a terephthalamide scaffold was selected to mimic the discontinuous binding epitopes of the Bak peptide (Yin and Hamilton, 2004) (Figure 3B). The designed compound 1a $(K i=$ $0.78 \mu \mathrm{M})$ inhibiting the $\mathrm{BH} 3$ domain disrupts the Bcl-xLBak complex with a comparable affinity to the peptide. The selected terephthalamide scaffold directly mimics the $\alpha$-helical region of $\mathrm{BH} 3$ domain in pro-apoptotic Bak and provides insight into further investigation for rigid small molecules against $\mathrm{Bcl}-\mathrm{xL}-\mathrm{Bak}$.

Despite their wide application, BH3 mimetic PPI inhibitors inevitably suffer from poor pharmacological properties (Touzeau et al., 2018). It is thus of intensive interest to academia to introduce constrained structure to rigidify peptides in their active conformations, pursuing for enhanced inhibitory activity. Walensky et al. (2004) exploited the hydrocarbon stapling strategy to obtain stapled peptides, which is named "stabilized alpha-helix of BCL-2 domains (SAHBs)." $\alpha, \alpha$-disubstituted unnatural amino acids with olefin-bearing tethers were used to generate hydrocarbon-stapled peptides by ruthenium catalyzed olefin metathesis. $\mathrm{SAHB}_{\mathrm{A}}$ simulating the $\mathrm{BH} 3$ domain of $\mathrm{BID}$ exhibited the high affinity of $K d=38.8 \mathrm{nM}$ compared to that of original $\mathrm{BH} 3$ peptide with more than six-fold improvement. In addition, lower molecular weight to promote bio-availability is another direction to improve the drug potential of peptidebased inhibitors. David P. Fairlie group have made an attempt to downsize the BAD BH3 domain based on long stapled peptides (Shepherd et al., 2016). They successfully cut down the BAD BH3 domain to $8-14$ residue peptides but still with appreciable affinity for Bcl-xL for PPI disruption.

Subsequent studies presented a panel of Bcl-2 family PPI inhibitors generated by side-chain cross-linking (Beekman et al., 2017). The first crystal structure of inhibitors among this class was reported for a biphenyl-cross-linked Noxa peptide in complex with its target Mcl-1 was determined to provide the structural insights to constructing selective $\mathrm{Mcl}$ 1 Inhibitors (Muppidi et al., 2012) (Figure 3C). Inhibitors derived from the sequence of the Mcl-1 $\mathrm{BH} 3$ motif were subsequently remodeled the surface by introducing side-chain replacement and $N$-methylation. They previously proposed a notion called dicysteine-mediated cross-linking chemistry, which applies distance-matching bisaryl cross-linkers to generate reinforced peptides and improve their cellular uptake. Following the strategy, researchers replaced $i$ and $i+7$ residues (Gln77, Lys-84) with two cysteines on the basis of the lead structure of NoxaB- (75-93)-C75A peptide and introduced biphenyl-cross-linker into the initial 19-mer peptide. Based on the aforementioned crystal structure, they determined key residues and finally obtained a series of optimized cross-linked peptides. The best peptidomimetic 1C showed a more than 30 fold increase in inhibitory potency and more preferable cell permeability as well as proteolytic stability (Figure 3D). This example highlights the significant application prospects of crosslinking and complementary peptide modification for future development of potential PPI therapeutics.

Library screening is another promising way to identify highaffinity peptide ligands in combination with computational design and rational mutagenesis (Dutta et al., 2015; Rezaei Araghi and Keating, 2016). The Keating group has developed peptides from a yeast-surface display library that target Bcl-xL, Mcl-1 or Bfl-1 with high affinity and selectivity (Foight et al., 2014; Rezaei Araghi et al., 2016). Importantly, the most specific peptide targeting Mcl-1 exhibited at least 40-fold specificity over four Bcl-2 homologs. It is encouraging that the high affinity peptide inhibitors for $\mathrm{Bcl}-2$ represent a starting point for further development of peptide-based therapeutics.

Extensive studies have inspired the advances in other novel methods of investigating peptide inhibitors. For example, Gorostizaa and Ernest Giralt group have recently conceived a modular design strategy based on a generalized template (GT) to obtain nano-switchable peptides that can be applied to $\alpha$-helix mediated PPIs (Nevola et al., 2019). They used the GT peptide approach combining the structural information from the PPI hot spots and finally developed series of light-regulated peptide inhibitors targeting Bcl-xL and Bak. Peptide-based inhibitors following this novel scheme not only retain favorable binding affinity but also possess the capacity to photo-switch in response to light stimulation. It can be applied to fine-tune the precise spatiotemporal regulation of PPIs and representative a novel prospective avenue in drug design and delivery.

The approaches above have been successfully applied to the design of Bcl-2 family PPI inhibitors. In general, in addition to mimicking the PPI hot spots, both the conformational flexibility and spatial arrangement of the peptide-based inhibitors scaffolds are of critical importance for consideration in molecule design. Moreover, novel techniques such as introducing specific cross-linking to rigidize structure and enhance stability against proteolysis are also emerging and expanding our arsenal in targeting PPIs. These successful strategies are instructive for further development of PPI drugs with higher efficiency and selectivity.

\section{Inhibitors of p53-MDM2}

The tumor suppressor gene p53 is known as a human transcription factor that induces cell-cycle arrest and apoptosis, in response to extrinsic stress and DNA damage (Wade et al., 2013). MDM2 and MDMX are considered as negative regulators of p53 through directly binding to its $\mathrm{N}$-terminus and mediate its degradation (Burgess et al., 2016). Amplification of MDM2 and MDMX are frequently observed in tumors harboring wild type p53 (Karni-Schmidt et al., 2016). Numerous studies have demonstrated that blocking p53-MDM2/MDMX interactions can release p53 from the inhibitory PPI complex and re-activate the p53-dependent cell 
death (Pazgier et al., 2009; Carvajal et al., 2018). Consequently, development of PPI inhibitors targeting p53-MDM2 interactions has emerged as a promising approach for the treatment of p53-related malignancy.

The p53 binding sites of MDM2 have been determined by X-ray crystallography (Kussie et al., 1996). p53-MDM2 interaction principally depends on the amphipathic $\alpha$-helix of the p53 and the MDM2 cleft lined with hydrophobic residues. In particular, three key residues in p53, Phe19, Trp23, and Leu26, insert into the MDM2 cleft mediating the proteins interaction. These critical interfacial structures all constitute the structural bases for p53-MDM2 PPI inhibitor discovery.
Peptidomimetic inhibitors featured with different backbones such as $\beta$-peptides (Burgess et al., 2016), peptoids (Estrada-Ortiz et al., 2016), and $N$-acylpolyamine (Teveroni et al., 2016) have been extensively studied for targeting p53-MDM2 interactions and they have also been exhaustively reviewed by most of previous excellent reviews (Henchey et al., 2010; Lao et al., 2014; Teveroni et al., 2016). On the other hand, unnatural peptide scaffolds or frameworks such as $\gamma$-AApeptides mimicking the secondary structure of native 553 peptide are gradually emerging as a new trend for p53-MDM2 PPI inhibitors. Thus, we mainly focus on them and review this novel category of compounds in current section, hoping to supply more insights toward drugging the critical p53-related PPIs as cancer therapeutics.

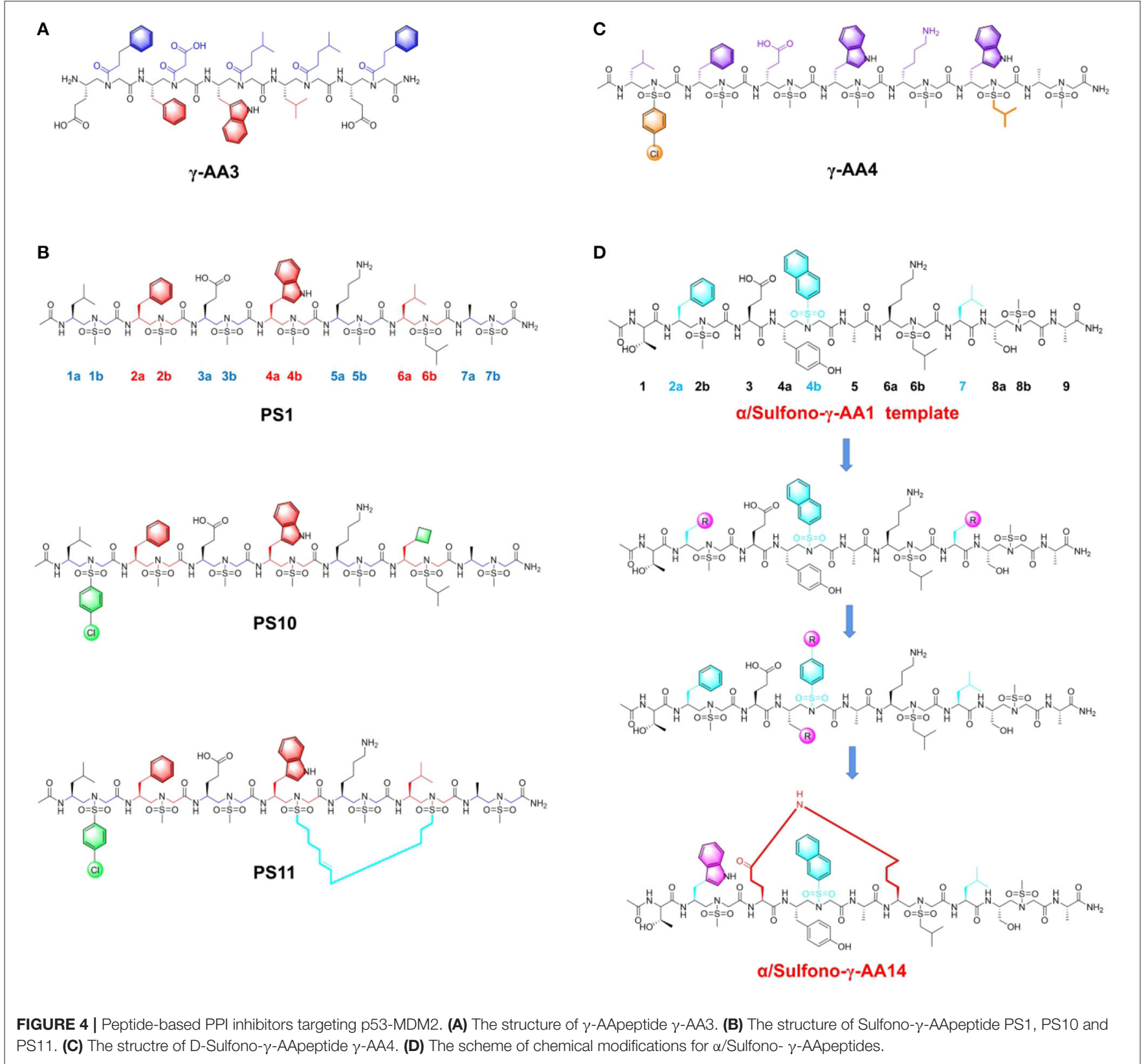


Niu et al. (2011) first proposed strategy for synthesis of several $\gamma$-AApeptide sequences with diverse side functional groups, which compared to canonical p53 mimicry peptide, display higher potency to inhibit p53-MDM2 interaction. They initially designed unique $\gamma$-AApeptide sequences based on the key Phe19, Trp23 and Leu26 residues from p53 implicated in PPI with MDM2 (Niu et al., 2011). In the synthetic route, $\gamma$-AApeptide building blocks were generated on a solid phase by adapting monomer building block strategy. ELISA results indicated that $\gamma$-AA3 (Figure 4A), as a new type of peptide mimic with an $\mathrm{IC}_{50}$ of $50 \mu \mathrm{M}$, is capable of disrupting p53-MDM2 interaction. Further computational modeling unveiled that the side chain moieties from $\boldsymbol{\gamma}$-AA3 overlap well with Phe19, Trp23, and Leu26 of the p53 helical domain, thereby conferring its inhibitory effect. Significantly, the $\boldsymbol{\gamma}$-AA3 showed outstanding resistance to enzymatic degradation as demonstrated by HPLC monitoring. These results suggested that $\gamma$-AApeptides are a series of promising lead compounds, expanding the peptidomimetics family in the application of blocking p53-MDM2 interaction.

Subsequently, the research priority is to further enhance inhibitory potency based on current frameworks. The investigators envisioned that previous bioactive peptides could not readily form the stable helical formation to fully mimic the interfacial structure of p53. Considering this regard, sulfonamide groups were introduced to the existing $\gamma$-AApeptides to induce the scaffold bending and increase their folding propensity (Teng et al., 2018). Consequently, sulfono- $\gamma$-AApeptides, the subclass of $\gamma$-AApeptides, were constructed to better simulate the p53 $\alpha$ helical conformation (Sang et al., 2020b). This series of peptides are stabilized by the intramolecular hydrogen bond interaction, which promotes their formation of $\alpha$-helix conformation in solution, thereby exhibiting enhanced PPI blocking efficacy. The researchers next designed sulfono- $\gamma$-AApeptides featured with chiral side chains at positions $2 \mathrm{a}, 4 \mathrm{a}$, and $6 \mathrm{a}$, which are identical to the crucial side chains of Phe19, Trp23, and Leu26 in p53. The first sulfono- $\gamma$-AApeptide sequence PS1 (Figure 4B), exhibited $\mathrm{IC}_{50}$ and $\mathrm{Kd}$ values of $3.95 \mu \mathrm{M}$ and $98 \mathrm{nM}$ toward MDM2. Then they fixed three key positions, including $2 \mathrm{a}, 4 \mathrm{a}$, and $6 \mathrm{a}$, and tried to modify the functional groups of other side chains in the sequence. When changing the methyl group to the cyclobutylmethyl group, the best inhibitor PS10 (Figure 4B), with $\mathrm{IC}_{50}$ and $\mathrm{Kd}$ values of $0.891 \mu \mathrm{M}$ and $26 \mathrm{nM}$ was obtained. The computational simulation results indicated that PS10 shares the similar binding mode of p53 in the hydrophobic cleft of MDM2. The strong binding affinity of PS10 is due to its intrinsic folding propensity. To improve the cell permeability, they also designed the stapled sulfono$\gamma$-AApeptide PS11 (Figure 4B), which exhibited remarkable cellular activity.

The above sulfono- $\gamma$-AApeptides are left-handed sequences, which attracts the curiosity of researchers to develop the $\mathrm{D}$ sulfono- $\gamma$-AApeptide right-handed helical foldamers (Sang et al., 2020a). As the enantiomers of known left-handed L-sulfono- $\gamma$-AApeptides, they could be accomplished by the similar strategy for synthesis. As expected, D-sulfono$\gamma$-AApeptide $\gamma$-AA4 (Figure 4C), bearing the replacement of Leu26 with Trp residues, possessed comparable binding affinity to its lead counterpart. Moreover, the peptide $\boldsymbol{\gamma}$-AA4 showed ideal low proteolytic susceptibility, which augments the potential of this new class of D-sulfono- $\gamma$-AApeptide in future biological applications.

To expand current scaffolds of peptidomimetic inhibitors and endow more chemical diversity in lead compounds, the investigators selected 1:1 right-handed $\alpha /$ Sulfono- $\gamma$-AA peptides as building block monomer for further modification. They chose specific positions $2 \mathrm{a}, 4 \mathrm{~b}$, and 7 of $1: 1 \alpha$ /sulfono- $\gamma$-AA peptides to simulate the Phe19, Trp23, and Leu26 in p53 (Shi et al., 2020). Initially, they investigated the effects of side chains containing different substituents on positions $2 \mathrm{a}$ and 7 (Figure 4D), which demonstrated that phenyl group and Leu were the optimal moieties at corresponding position. Then they explored the importance of side chain at the position $4 \mathrm{~b}$. Classic structural modification strategies were applied to optimize the existing framework, such as changing substituents on the benzene ring or introducing aromatic rings with different sizes. It is demonstrated that these peptidomimetic inhibitors bind more tightly toward MDM2 than the original p53 peptide. Finally, they achieved the most potent helical heterogeneous $1: 1 \alpha /$ Sulfono- $\boldsymbol{\gamma}$-AA1 (Figure 4D), which revealed the binding affinity to MDM2 and MDMX, with $\mathrm{Kd}$ of $19.3 \mathrm{nM}$ and $66.8 \mathrm{nM}$, respectively. It displayed an 18-fold higher binding affinity toward MDM2 than the native p53 peptide. In addition, cross-linking strategy was also utilized into the optimization efforts. Lactam bridge with amide bonds were built to rigidify the main scaffold and improve the cellular inhibitory function. The best stapled peptide $\alpha /$ Sulfono- $\gamma$-AA14 (Figure $4 \mathrm{D}$ ), with an $\mathrm{IC}_{50}$ value of $4.9 \mu \mathrm{M}$, was capable of disrupting p53-MDM2 and resisting enzymatic hydrolysis.

All the bioactive peptides, including $\gamma$-AApeptide, sulfono$\gamma$-AApeptide, and 1:1 $\alpha /$ Sulfono- $\gamma$-AA peptide, show distinctive potency in the inhibition of p53 and MDM2 interaction. Continuous endeavors are devoted to optimizing unnatural peptide backbones, so as to obtain more stable $\alpha$-helical conformation and higher potent mimicry of regular peptide. The rational design of peptidomimetics targeting p53-MDM2 opens the window for explorations and applications of new class of unnatural peptide sequences toward other therapeutic disease targets.

\section{Inhibitors of APC-Asef Interaction}

Colorectal cancer is one of the major public health threats in modern society, and its pathogenesis involves both genetic and environmental factors. One of the oncogenes for colorectal cancer is Adenomatous Polyposis Coli (APC), whose mutations have been detected in more than $30 \%$ of colon cancer patients (Kawasaki et al., 2000). Upon genetic lesions, APC gene will be translated into a truncated form of protein, which binds and constitutively activates its receptor Asef. PPI between truncated APC and Asef relieves Asef from autoinhibition and traps it in an abnormally active state for its guanine nucleotide exchange factor (GEF) activity. It further triggers the downstream oncogenic signals, leading to tumorigenesis and metastasis (Kwong and Dove, 2009; Oh et al., 2018). Thus, the APC-Asef interaction has attracted considerable interests as a 
A

MAI-150

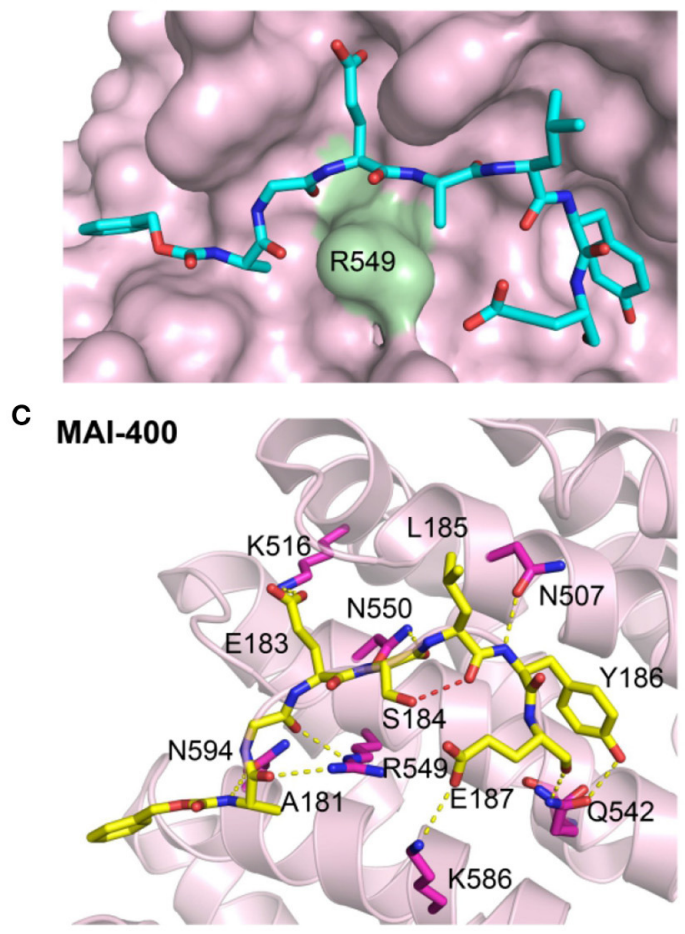

B

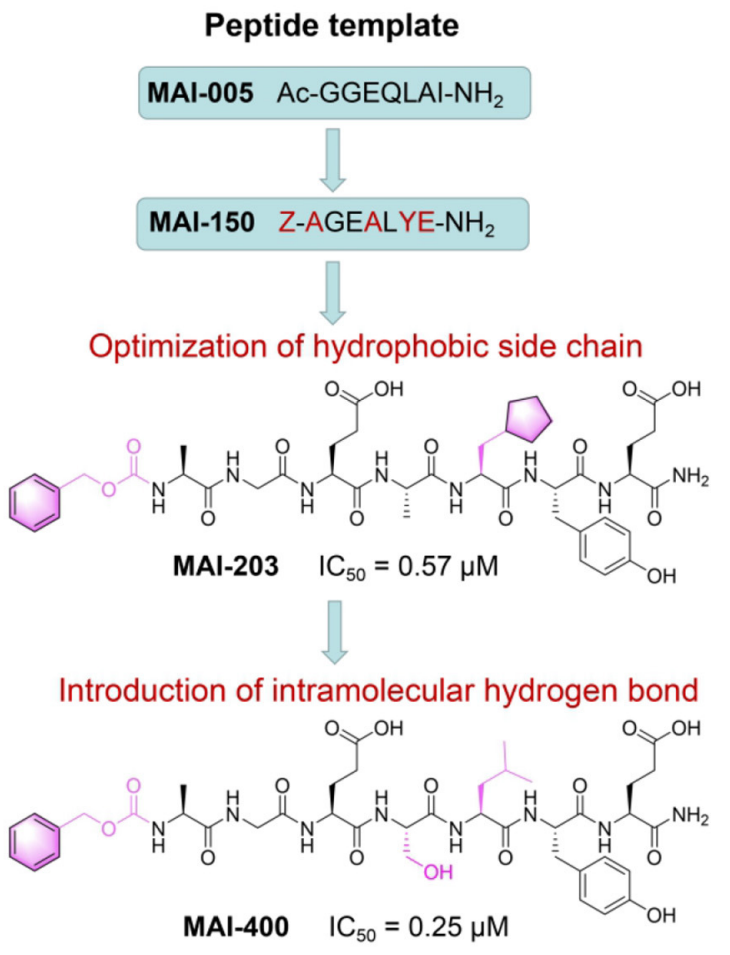

FIGURE 5 | Peptide-based PPI inhibitors targeting APC-Asef PPI. (A) Structural overview of MAl150/APC PPI complex (PDB ID: 5IZ6). APC is shown as a solvent-accessible surface (pink), and MAl-150 is depicted by sticks (carbon atoms: cyan). (B) Development scheme of MAl analogs as APC-Asef PPI inhibitors. (C) Binding interactions between MAl-400 (carbon atoms: yellow) and APC (carbon atoms: pink). The red dashed lines represent the intramolecular hydrogen bonds between MAl-400 and APC.

highly enticing target for colorectal cancer therapy exploiting PPI inhibitors.

Zhang et al. have recently reported a series of first-in-class peptidomimetic inhibitors through structure-based rational drug design that potently block the interaction between APC and Asef (Jiang et al., 2017). Based on the previously resolved crystal structure of APC-Asef complex, they identified the segment from Asef as the principal mediator for the PPI. Through mutagenesis and truncated peptide screening, hot-spot residues within for APC-Asef PPI were revealed and a primary peptidomimetics template MAI-005 ( ${ }^{181}$ GGEQLAI $\left.^{187}\right)$ was designed accordingly. After another round of mutagenesis screening and related crystallography study, a 7-mer peptide library based on the optimized scaffold ${ }^{181} \mathrm{AGEAL}^{185}$ was generated. Exhaustive testing with this peptidomimetics library yielded a crucial peptide inhibitor MAI-150 ( ${ }^{181}$ AGEALYE $\left.^{187}\right)$ with a Ki value of $0.12 \mu \mathrm{M}$ that was 370 -fold enhanced compared to the original template MAI-005. Crystallography study revealed that in apo state, PPI interface of APC-Asef complex was flat and wide, conferring great difficulties for ligand binding. However, upon inhibitor loading and during its interactions with APC, through "inducefit" effects, the Arg549 in APC protruded out from the PPI interface and facilitated the formation of a more "druggable" conformation that the peptide inhibitor could bind more easily
(Figure 5A). Further cellular and animal model experiments all demonstrated the promising efficacy of these inhibitor peptides. Such study not only reported series of prospective first-in-class peptidomimetics inhibitor targeting the APC-Asef PPI, but also exemplified the possibility of utilizing "induce-fit" mechanistic to tame traditional intractable target. It represented a novel direction for colorectal therapeutics as well as a new avenue for PPI drug discovery.

To improve the inhibitory activity, the researchers carried out another round of modifications based on the aforementioned "druggable" conformation, focusing on the capping groups of the peptidomimetics, especially the side chains of Leu185 and Tyr186 (Yang et al., 2018). Through multiple screening, a cyclopentyalanin-derived peptidomimetic inhibitor MAI-203 was identified as an enhanced compound, which exhibited an eight-fold improvement relative to MAI-150, with a $\mathrm{Ki}$ of $0.015 \mu \mathrm{M}$ and a $\mathrm{Kd}$ of $0.036 \mu \mathrm{M}$. In order to further optimize the inhibitor peptidomimetics, researchers exploited a rational design strategy of intramolecular hydrogen bonds and introduced such interaction through modifying the lipophilic substituents at the position 185 of MAI-150. As a result, a best-in-class peptidomimetic inhibitor MAI-400 was discovered (Figure 5B). It displayed improved binding affinity toward APC with an $\mathrm{IC}_{50}$ of $0.25 \mu \mathrm{M}$ and a $\mathrm{Kd}$ of $0.012 \mu \mathrm{M}$. The crystal 
structure of MAI-400/APC complex revealed that MAI-400 indeed formed an intramolecular hydrogen bond between Ser184 and Leu185. Notably, this hydrogen bond effectively constrained inhibitor's conformation at the binding core along APC surface, contributing to its improved binding and optimized inhibitory performances (Figure 5C).

Collectively, these studies provided a significant example for structured-based design of potent peptidomimetic inhibitors, where through utilizing protein dynamic ensemble and "inducefit" mechanistic and harnessing rational drug design strategies such as intramolecular hydrogen bond introduction, peptidebased PPI inhibitors could achieved considerable improvement in binding affinity and inhibitory efficacy. Such researches not only shed light on therapeutic agent targeting APC-Asef PPI for colon cancer, but also open a new stream for peptidomimetics PPI inhibitor drug development.

\section{DISCUSSION AND CONCLUSION}

As the pivotal nexus of a broad range of biological and cellular events, PPIs are considered to be one of the utmost important drug target pools in modern medicine. However, historically, this tempting repertoire remains poorly studied and unexplored owing to its unfavorable biochemical and biophysical properties. In the campaign to tame this class of refractory targets, one of the key powerful armory is peptide-based inhibitors, which mimic the PPI binding partners and readily interfere with the PPI systems of pharmaceutical interests. To date, over 60 peptide drugs targeting PPIs have entered into market and clinical applications (Lee et al., 2019), but their development and optimizations still frequently encounter obstacles. One of the vital difficulties in PPI inhibitor discovery is the intractable interfacial structures, which are generally wide and flat and lack well-defined pockets for binding. A potential strategy to tackle this problem is utilizing the induce-fit effect of the target proteins (Nussinov et al., 2014). Upon the inhibitor-protein interactions, the protein structures will be subtly altered, which triggers the surface conformational changes, thereby facilitating the more compact binding of the inhibitors. Importantly, the rapid advances in structural biology and computational biology have enabled the in-depth exploration into the sophisticated conformational ensembles of PPI systems (Qiu et al., 2020; Wang et al., 2021). With the help of techniques such as molecular dynamics (MD) simulations (Yang et al., 2019), the transient intermediate PPI interface conformations can be probed, based on which further structure-based rational inhibitor design can be more easily carried out (Tavakoli and Ganjalikhany, 2019; Yao et al., 2020). Generally, rational design of peptide-based inhibitors toward PPIs depends heavily on reported crystal structures, which can specifically reveal the principles of proteinprotein binding modes. It is significant to develop novel molecular scaffolds with an in-depth understanding of the hot spot residues in each interface. In addition, novel peptide-based inhibitors could be more efficiently identified, by combining the computer simulation with chemical structure insights to
TABLE 1 | Major obstacles in peptide-based PPI inhibitors design and the representative solutions.

\begin{tabular}{ll}
\hline Obstacles & Solutions \\
\hline Hydrophobicity & Charged/polar residues incorporation \\
Stability & Capping additions (acetylation and amidation) \\
& Cyclization/disulfide bonds \\
& Hydrocarbon stapled peptides \\
& D-amino acid replacement \\
& Unnatural amino acid modifications \\
& Peptoids
\end{tabular}

Renal clearance Macromolecules/polymers conjugations

Permeability Stapled peptides/cell-penetrating peptides

continuously perform high-throughput screening. For example, SLC (Split-Luciferase Complementation) and HPSEC (highperformance and high-pressure size exclusion chromatography) are recently developed as two novel screening platforms in vitro, which have the potential to perform in high-throughput screening of PPI inhibitors. They can overcome the shortcomings of high false positives in regular cell-based methods. SLC was very recently developed by Zhang et al. and through this approach, they have successfully identified two influenza virus PPI inhibitors with broad spectrum antiviral activity (Zhang et al., 2020). As for HPSEC, utilizing the chromatography techniques, it can screen tens of thousands of sequences bearing unnatural amino acids based on size exclusion, achieving higher efficiency and accuracy (Touti et al., 2019). Most of the peptide inhibitors obtained are with high affinity, and most are with nanomolar levels. Besides, chemical modification is indeed an overwhelming strategy to optimize existing molecular scaffolds because the intrinsic properties of PPI inhibitors frequently hamper their successful translation into clinic. Since the PPI partners are mostly large and bulky, their corresponding peptidebased PPI inhibitors are inevitably of relatively large size and high molecular weight, which confer difficulty in their cell membrane permeability and bioavailability. Pharmacological properties and drug-like potential are still required to be optimized in following attempts like hydrocarbon stapling (Chang et al., 2013) and cell-penetrating peptide conjugations (Philippe et al., inpress). Moreover, introduction of D-amino acids, lactam cross-linker or macrocycle (Lautrette et al., 2016; Magiera-Mularz et al., 2017) into the scaffold is beneficial to enhance the metabolic stability (Table 1). Notably, development of small molecules based on the peptide backbone is among the trends in current medicinal studies (Gao et al., 2016; Wang et al., 2019). Without doubt, it is an ever challenging task to design small molecules possessing rigid and hydrophobic features by downsizing the molecular size and mimicking key residues of original peptides (Wang et al., 2019).

In summary, with advancement for design techniques, more high-potent and low-toxic peptide drugs could be discovered via rational structure-based design. We could be cautiously optimistic that the next decades will witness new classes of 
peptide-based inhibitors as promising drug candidates emerging on the market.

\section{AUTHOR CONTRIBUTIONS}

SL conceived and supervised the project. XW and DN analyzed the results and drafted the manuscript. SL and YL revised

\section{REFERENCES}

Adams, J. M., and Cory, S. (2018). The Bcl-2 arbiters of apoptosis and their growing role as cancer targets. Cell Death Differ. 25, 27-36. doi: 10.1038/cdd.2017.161

Akram, O. N., DeGraff, D. J., Sheehan, J. H., Tilley, W. D., Matusik, R. J., Ahn, J. M., et al. (2014). Tailoring peptidomimetics for targeting protein-protein interactions. Mol. Cancer Res. 12, 967-978. doi: 10.1158/1541-7786.MCR-13-0611

Ashkenazi, A., Fairbrother, W. J., Leverson, J. D., and Souers, A. J. (2017). From basic apoptosis discoveries to advanced selective Bcl-2 family inhibitors. Nat. Rev. Drug Discov. 16, 273-284. doi: 10.1038/nrd.2016.253

Bartling, C. R. O., Jensen, T. M. T., Henry, S. M., Colliander, A. L., Sereikaite, V., Wenzler, M., et al. (2021). Targeting the App-Mint2 protein-protein interaction with a peptide-based inhibitor reduces amyloid-beta formation. J. Am. Chem. Soc. 143, 891-901. doi: 10.1021/jacs.0c10696

Beekman, A. M., O'Connell, M. A., and Howell, L. A. (2017). Peptide-directed binding for the discovery of modulators of alpha-helix-mediated proteinprotein interactions: proof-of-concept studies with the apoptosis regulator Mcl1. Angew. Chem. Int. Ed. Engl. 56, 10446-10450. doi: 10.1002/anie.201705008

Bogan, A. A., and Thorn, K. S. (1998). Anatomy of hot spots in protein interfaces. J. Mol. Biol. 280, 1-9. doi: 10.1006/jmbi.1998.1843

Burgess, A., Chia, K. M., Haupt, S., Thomas, D., Haupt, Y., and Lim, E. (2016). Clinical overview of Mdm2/X-targeted therapies. Front. Oncol. 6:7. doi: $10.3389 /$ fonc. 2016.00007

Carvajal, L. A., Neriah, D. B., Senecal, A., Benard, L., Thiruthuvanathan, V., Yatsenko, T., et al. (2018). Dual inhibition of Mdmx and Mdm2 as a therapeutic strategy in Leukemia. Sci. Transl. Med. 10:eaao3003. doi: 10.1126/scitranslmed.aao3003

Chang, Y. S., Graves, B., Guerlavais, V., Tovar, C., Packman, K., To, K. H., et al. (2013). Stapled alpha-helical peptide drug development: a potent dual inhibitor of Mdm2 and Mdmx for P53-dependent cancer therapy. Proc. Natl. Acad. Sci. U.S.A. 110, E3445-3454. doi: 10.1073/pnas.1303002110

Chen, L., Zhuang, C., Lu, J., Jiang, Y., and Sheng, C. (2018). Discovery of novel kras-pdedelta inhibitors by fragment-based drug design. J. Med. Chem. 61, 2604-2610. doi: 10.1021/acs.jmedchem.8b00057

Chen, P. L., Wang, M., Ou, W. C., Lii, C. K., Chen, L. S., and Chang, D. (2001). Disulfide bonds stabilize Jc virus capsid-like structure by protecting calcium ions from chelation. FEBS Lett. 500, 109-113. doi: 10.1016/S0014-5793 (01)02598-4

Chene, P. (2006). Drugs targeting protein-protein interactions. ChemMedChem 1, 400-411. doi: $10.1002 / \mathrm{cmdc} .200600004$

Chittenden, T. (2002). Bh3 domains: intracellular death-ligands critical for initiating apoptosis. Cancer Cell. 2, 165-166. doi: 10.1016/S1535-6108 (02)00128-9

Choudhary, A., and Raines, R. T. (2011). An evaluation of peptide-bond isosteres. Chembiochem 12, 1801-1807. doi: 10.1002/cbic.201100272

Cunningham, A. D., Qvit, N., and Mochly-Rosen, D. (2017). Peptides and peptidomimetics as regulators of protein-protein interactions. Curr. Opin. Struct. Biol. 44, 59-66. doi: 10.1016/j.sbi.2016.12.009

Davenport, A. P., Scully, C. C. G., de Graaf, C., Brown, A. J. H., and Maguire, J. J. (2020). Advances in therapeutic peptides targeting G protein-coupled receptors. Nat. Rev. Drug Discov. 19, 389-413. doi: 10.1038/s41573-020-0062-z

de la Fuente-Nunez, C., Reffuveille, F., Mansour, S. C., Reckseidler-Zenteno, S. L., Hernandez, D., Brackman, G., et al. (2015). D-enantiomeric peptides that eradicate wild-type and multidrug-resistant biofilms and protect the manuscript. All authors discussed the results and reviewed the manuscript.

\section{ACKNOWLEDGMENTS}

This research was sponsored by National Natural Science Foundation of China (22077082 and 21778037).

against lethal pseudomonas aeruginosa infections. Chem. Biol. 22, 196-205. doi: 10.1016/j.chembiol.2015.01.002

Deeks, E. D. (2016). Venetoclax: first global approval. Drugs 76, 979-987. doi: $10.1007 / \mathrm{s} 40265-016-0596-x$

Denis, C., Sopkova-de Oliveira Santos, J., Bureau, R., and Voisin-Chiret, A. S. (2020). Hot-spots of Mcl-1 protein. J. Med. Chem. 63, 928-943. doi: 10.1021/acs.jmedchem.9b00983

Devkota, P., and Wuchty, S. (2020). Controllability analysis of molecular pathways points to proteins that control the entire interaction network. Sci. Rep. 10:2943. doi: 10.1038/s41598-020-59717-6

Di, L. (2015). Strategic approaches to optimizing peptide adme properties. AAPS J. 17, 134-143. doi: 10.1208/s12248-014-9687-3

Dutta, S., Ryan, J., Chen, T. S., Kougentakis, C., Letai, A., and Keating, A. E. (2015). Potent and specific peptide inhibitors of human pro-survival protein Bcl-Xl. J. Mol. Biol. 427, 1241-1253. doi: 10.1016/j.jmb.2014.09.030

Estrada-Ortiz, N., Neochoritis, C. G., and Domling, A. (2016). How to design a successful P53-Mdm2/X interaction inhibitor: a thorough overview based on crystal structures. ChemMedChem 11, 757-772. doi: 10.1002/cmdc.201500487

Fedorczyk, B., Lipinski, P. F. J., Puszko, A. K., Tymecka, D., Wilenska, B., Dudka, W., et al. (2019). Triazolopeptides inhibiting the interaction between Neuropilin-1 and vascular endothelial growth factor-165. Molecules 24:1756. doi: 10.3390/molecules 24091756

Foight, G. W., Ryan, J. A., Gulla, S. V., Letai, A., and Keating, A. E. (2014). Designed Bh3 peptides with high affinity and specificity for targeting Mcl-1 in cells. ACS Chem. Biol. 9, 1962-1968. doi: 10.1021/cb500340w

Gao, J., Wang, T., Qiu, S., Zhu, Y., Liang, L., and Zheng, Y. (2016). Structure-based drug design of small molecule peptide deformylase inhibitors to treat cancer. Molecules 21, 396. doi: 10.3390/molecules21040396

Halperin, I., Wolfson, H., and Nussinov, R. (2004). Protein-protein interactions; coupling of structurally conserved residues and of hot spots across interfaces. Implications Docking Struct. 12, 1027-1038. doi: 10.1016/j.str.2004.04.009

He, X., Huang, N., Qiu, Y., Zhang, J., Liu, Y., Yin, X. L., et al. (2021). Conformational selection mechanism provides structural insights into the optimization of Apc-Asef inhibitors. Molecules 26:962. doi: 10.3390/molecules26040962

Henchey, L. K., Porter, J. R., Ghosh, I., and Arora, P. S. (2010). High specificity in protein recognition by hydrogen-bond-surrogate A-Helices: selective inhibition of the P53/Mdm2 complex. ChemBioChem 11, 2104-2107. doi: 10.1002/cbic. 201000378

Isvoran, A., Craciun, D., Martiny, V., Sperandio, O., and Miteva, M. A. (2013). Computational analysis of protein-protein interfaces involving an alpha helix: insights for terphenyl-like molecules binding. BMC Pharmacol. Toxicol. 14:31. doi: 10.1186/2050-6511-14-31

Ji, C., Wang, S., Chen, S., He, S., Jiang, Y., Miao, Z., et al. (2017). Design, synthesis and biological evaluation of novel antitumor spirotetrahydrothiopyranoxindole derivatives as potent P53-Mdm2 inhibitors. Bioorg. Med. Chem. 25, 5268-5277. doi: 10.1016/j.bmc.2017.07.049

Jiang, H., Deng, R., Yang, X., Shang, J., Lu, S., Zhao, Y., et al. (2017). Peptidomimetic Inhibitors of Apc-Asef interaction block colorectal cancer migration. Nat. Chem. Biol. 13, 994-1001. doi: 10.1038/nchembio.2442

Kale, J., Osterlund, E. J., and Andrews, D. W. (2018). Bcl-2 Family proteins: changing partners in the dance towards death. Cell Death Differ. 25, 65-80. doi: $10.1038 /$ cdd.2017.186

Karatas, H., Townsend, E. C., Cao, F., Chen, Y., Bernard, D., Liu, L., et al. (2013). High-affinity, small-molecule peptidomimetic inhibitors of 
Mll1/Wdr5 protein-protein interaction. J. Am. Chem. Soc. 135, 669-682. doi: $10.1021 /$ ja306028q

Karni-Schmidt, O., Lokshin, M., and Prives, C. (2016). The roles of Mdm2 and Mdmx in cancer. Annu. Rev. Pathol. 11, 617-644. doi: 10.1146/annurev-pathol-012414-040349

Kawasaki, Y., Senda, T., Ishidate, T., Koyama, R., Morishita, T., Iwayama, Y., et al. (2000). Asef, a link between the tumor suppressor Apc and G-protein signaling. Science 289, 1194-1197. doi: 10.1126/science.289.5482.1194

Klein, J. S., Jiang, S., Galimidi, R. P., Keeffe, J. R., and Bjorkman, P. J. (2014). Design and characterization of structured protein linkers with differing flexibilities. Protein. Eng. Des. Sel. 27, 325-330. doi: 10.1093/protein/gzu043

Knight, T., Luedtke, D., Edwards, H., Taub, J. W., and Ge, Y. (2019). A delicate balance - the Bcl-2 family and its role in apoptosis, oncogenesis, and cancer therapeutics. Biochem. Pharmacol. 162, 250-261. doi: 10.1016/j.bcp.2019.01.015

Koh, G. C., Porras, P., Aranda, B., Hermjakob, H., and Orchard, S. E. (2012). Analyzing protein-protein interaction networks. J. Proteome Res. 11, 2014-2031. doi: 10.1021/pr201211w

Kotschy, A., Szlavik, Z., Murray, J., Davidson, J., Maragno, A. L., Le ToumelinBraizat, G., et al. (2016). The Mcl1 inhibitor S63845 is tolerable and effective in diverse cancer models. Nature 538, 477-482. doi: 10.1038/nature19830

Kussie, P. H., Gorina, S., Marechal, V., Elenbaas, B., Moreau, J., Levine, A. J., et al. (1996). Structure of the Mdm2 oncoprotein bound to the P53 tumor suppressor transactivation domain. Science 274, 948-953. doi: $10.1126 /$ science. 274.5289 .948

Kwong, L. N., and Dove, W. F. (2009). Apc and its modifiers in colon cancer. Adv. Exp. Med. Biol. 656, 85-106. doi: 10.1007/978-1-4419-1145-2_8

Lao, B. B., Drew, K., Guarracino, D. A., Brewer, T. F., Heindel, D. W., Bonneau, R., et al. (2014). Rational design of topographical helix mimics as potent inhibitors of protein-protein interactions. J. Am. Chem. Soc. 136, 7877-7888. doi: $10.1021 /$ ja502310r

Lau, J. L., and Dunn, M. K. (2018). Therapeutic peptides: historical perspectives, current development trends, and future directions. Bioorg. Med. Chem. 26, 2700-2707. doi: 10.1016/j.bmc.2017.06.052

Lautrette, G., Touti, F., Lee, H. G., Dai, P., and Pentelute, B. L. (2016). Nitrogen arylation for macrocyclization of unprotected peptides. J. Am. Chem. Soc. 138, 8340-8343. doi: 10.1021/jacs.6b03757

Lee, A. C., Harris, J. L., Khanna, K. K., and Hong, J. H. (2019). A comprehensive review on current advances in peptide drug development and design. Int. J. Mol. Sci. 20:2383. doi: 10.3390/ijms20102383

Lenci, E., and Trabocchi, A. (2020). Peptidomimetic toolbox for drug discovery. Chem. Soc. Rev. 49, 3262-3277. doi: 10.1039/D0CS00102C

Li, H. Y., Zawahir, Z., Song, L. D., Long, Y. Q., and Neamati, N. (2006). Sequence-based design and discovery of peptide inhibitors of Hiv-1 integrase: insight into the binding mode of the enzyme. J. Med. Chem. 49, 4477-4486. doi: $10.1021 /$ jm060307u

Li, J., Zhu, R., Chen, K., Zheng, H., Zhao, H., Yuan, C., et al. (2018). Potent and specific Atg8-targeting autophagy inhibitory peptides from giant ankyrins. Nat. Chem. Biol. 14, 778-787. doi: 10.1038/s41589-018-0082-8

Li, X., Dai, J., Ni, D., He, X., Zhang, H., Zhang, J., et al. (2020). Insight into the mechanism of allosteric activation of Pi3kalpha by oncoprotein K-Ras4b. Int. J. Biol. Macromol. 144, 643-655. doi: 10.1016/j.ijbiomac.2019.12.020

Lim, H., Chun, J., Jin, X., Kim, J., Yoon, J., and No, K. T. (2019). Investigation of protein-protein interactions and hot spot region between Pd-1 and Pd-L1 by fragment molecular orbital method. Sci. Rep. 9:16727. doi: 10.1038/s41598-019-53216-Z

Lin, A., Giuliano, C. J., Palladino, A., John, K. M., Abramowicz, C., Yuan, M. L., et al. (2019). Off-target toxicity is a common mechanism of action of cancer drugs undergoing clinical trials. Sci. Transl. Med. 11:eaaw8412. doi: 10.1126/scitranslmed.aaw8412

Liu, J., Ying, J., Chow, V. T., Hruby, V. J., and Satyanarayanajois, S. D. (2005). Structure-activity studies of peptides from the "hot-spot" region of human $\mathrm{Cd} 2$ protein: development of peptides for immunomodulation. J. Med. Chem. 48, 6236-6249. doi: 10.1021/jm0503547

Liu, L., Ghosh, N., Slivka, P. F., Fiorini, Z., Hutchinson, M. R., Watkins, L. R., et al. (2011). An Md2 hot-spot-mimicking peptide that suppresses Tlr4-mediated inflammatory response in vitro and in vivo. Chembiochem 12, 1827-1831. doi: $10.1002 /$ cbic. 201100211
Lo Conte, L., Chothia, C., and Janin, J. (1999). The atomic structure of protein-protein recognition sites. J. Mol. Biol. 285, 2177-2198. doi: 10.1006/jmbi.1998.2439

Luck, K., Kim, D. K., Lambourne, L., Spirohn, K., Begg, B. E., Bian, W., et al. (2020). A reference map of the human binary protein interactome. Nature 580, 402-408. doi: 10.1038/s41586-020-2188-x

Magiera-Mularz, K., Skalniak, L., Zak, K. M., Musielak, B., Rudzinska-Szostak, E., Berlicki, L., et al. (2017). Bioactive macrocyclic inhibitors of the Pd1/Pd-L1 immune checkpoint. Angew. Chem. Int. Ed. Engl. 56, 13732-13735. doi: 10.1002/anie.201707707

Milroy, L. G., Grossmann, T. N., Hennig, S., Brunsveld, L., and Ottmann, C. (2014). Modulators of protein-protein interactions. Chem. Rev. 114, 4695-4748. doi: $10.1021 / \mathrm{cr} 400698 \mathrm{c}$

Muppidi, A., Doi, K., Edwardraja, S., Drake, E. J., Gulick, A. M., Wang, H. G., et al. (2012). Rational design of proteolytically stable, cell-permeable peptide-based selective Mcl-1 inhibitors. J. Am. Chem. Soc. 134, 14734-14737. doi: $10.1021 /$ ja306864v

Nevola, L., Varese, M., Martin-Quiros, A., Mari, G., Eckelt, K., Gorostiza P., et al. (2019). Targeted nanoswitchable inhibitors of protein-protein interactions involved in apoptosis. ChemMedChem. 14, 100-106. doi: $10.1002 / \mathrm{cmdc} .201800647$

Ni, D., Lu, S., and Zhang, J. (2019). Emerging roles of allosteric modulators in the regulation of protein-protein interactions (Ppis): a new paradigm for Ppi drug discovery. Med. Res. Rev. 39, 2314-2342. doi: 10.1002/med.21585

Nimmagadda, A., Shi, Y., and Cai, J. (2019). Gamma-aapeptides as a new strategy for therapeutic development. Curr. Med. Chem. 26, 2313-2329. doi: 10.2174/0929867324666171107095913

Niu, Y., Hu, Y., Li, X., Chen, J., and Cai, J. (2011). $\Gamma$-aapeptides: design, synthesis and evaluation. New J. Chem. 35, 542-545. doi: 10.1039/c0nj00943a

Nussinov, R., Ma, B., and Tsai, C. J. (2014). Multiple conformational selection and induced fit events take place in allosteric propagation. Biophys. Chem. 186, 22-30. doi: 10.1016/j.bpc.2013.10.002

Oh, J. Y., Lim, C. S., Yoo, K. S., Park, H., Park, Y. S., Kim, E. G., et al. (2018). Adenomatous polyposis coli-stimulated Gef 1 (Asef1) is a negative regulator of excitatory synaptic function. J. Neurochem. 147, 595-608. doi: 10.1111 /jnc. 14570

Pallerla, S., Naik, H., Singh, S., Gauthier, T., Sable, R., and Jois, S. D. (2018). Design of cyclic and D-amino acids containing peptidomimetics for inhibition of protein-protein interactions of Her2-Her3. J. Pept. Sci. 24:e3066. doi: $10.1002 / p s c .3066$

Pazgier, M., Liu, M., Zou, G., Yuan, W., Li, C., Li, C., et al. (2009). Structural basis for high-affinity peptide inhibition of P53 interactions with Mdm2 and Mdmx. Proc. Natl. Acad. Sci. U.S.A. 106, 4665-4670. doi: 10.1073/pnas.0900947106

Pelay-Gimeno, M., Glas, A., Koch, O., and Grossmann, T. N. (2015). Structure-based design of inhibitors of protein-protein interactions: mimicking peptide binding epitopes. Angew. Chem. Int. Ed. Engl. 54, 8896-8927. doi: 10.1002/anie.201412070

Philippe, G. J. B., Craik, D. J., and Henriques, S. T. (inpress). Converting peptides into drugs targeting intracellular protein-protein interactions. Drug Discov. Today. doi: 10.1016/j.drudis.2021.01.022

Qiu, Y., Li, X., He, X., Pu, J., Zhang, J., and Lu, S. (2020). Computational methodsguided design of modulators targeting protein-protein interactions (Ppis). Eur. J. Med. Chem. 207:112764. doi: 10.1016/j.ejmech.2020.112764

Quartararo, J. S., Wu, P., and Kritzer, J. A. (2012). Peptide bicycles that inhibit the Grb2 Sh2 domain. Chembiochem 13, 1490-1496. doi: 10.1002/cbic.201200175

Qvit, N., Rubin, S. J. S., Urban, T. J., Mochly-Rosen, D., and Gross, E. R. (2017). Peptidomimetic therapeutics: scientific approaches and opportunities. Drug Discov. Today 22, 454-462. doi: 10.1016/j.drudis.2016.11.003

Ran, X., and Gestwicki, J. E. (2018). Inhibitors of protein-protein interactions (Ppis): an analysis of scaffold choices and buried surface area. Curr. Opin. Chem. Biol. 44, 75-86. doi: 10.1016/j.cbpa.2018.06.004

Rezaei Araghi, R., and Keating, A. E. (2016). Designing helical peptide inhibitors of protein-protein interactions. Curr. Opin. Struct. Biol. 39, 27-38. doi: 10.1016/j.sbi.2016.04.001

Rezaei Araghi, R., Ryan, J. A., Letai, A., and Keating, A. E. (2016). Rapid optimization of Mcl-1 inhibitors using stapled peptide libraries including non-natural side chains. ACS Chem. Biol. 11, 1238-1244. doi: $10.1021 /$ acschembio.5b01002 
Robinson, J. A. (2008). Beta-hairpin peptidomimetics: design, structures and biological activities. ACC Chem. Res. 41, 1278-1288. doi: 10.1021/ar700259k

Ryan, C. E., and Davids, M. S. (2019). Bcl-2 inhibitors, present and future. Cancer J. 25, 401-409. doi: 10.1097/PPO.0000000000000408

Sang, P., Shi, Y., Higbee, P., Wang, M., Abdulkadir, S., Lu, J., et al. (2020a). Rational design and synthesis of right-handed D-sulfono-gamma-aapeptide helical foldamers as potent inhibitors of protein-protein interactions. J. Org. Chem. 85, 10552-10560. doi: 10.1021/acs.joc.0c00996

Sang, P., Shi, Y., Lu, J., Chen, L., Yang, L., Borcherds, W., et al. (2020b). Alpha-helix-mimicking sulfono-gamma-aapeptide inhibitors for P53Mdm2/Mdmx protein-protein interactions. J. Med. Chem. 63, 975-986. doi: 10.1021/acs.jmedchem.9b00993

Sang, P., Zhang, M., Shi, Y., Li, C., Abdulkadir, S., Li, Q., et al. (2019). Inhibition of beta-catenin/B cell lymphoma 9 protein-protein interaction using alpha-helixmimicking sulfono-gamma-aapeptide inhibitors. Proc. Natl. Acad. Sci. U.S.A. 116, 10757-10762. doi: 10.1073/pnas.1819663116

Sattler, M., Liang, H., Nettesheim, D., Meadows, R. P., Harlan, J. E., Eberstadt, M., et al. (1997). Structure of Bcl-Xl-bak peptide complex: recognition between regulators of apoptosis. Science 275, 983-986. doi: $10.1126 /$ science.275.5302.983

Schatti, J., Sezer, U., Pedalino, S., Cotter, J. P., Arndt, M., Mayor, M., et al. (2017). Tailoring the volatility and stability of oligopeptides. J. Mass Spectrom. 52, 550-556. doi: 10.1002/jms.3959

Schmidt, T., Bergner, A., and Schwede, T. (2014). Modelling three-dimensional protein structures for applications in drug design. Drug Discov. Today 19, 890-897. doi: 10.1016/j.drudis.2013.10.027

Scott, D. E., Bayly, A. R., Abell, C., and Skidmore, J. (2016). Small molecules, big targets: drug discovery faces the protein-protein interaction challenge. Nat. Rev. Drug Discov. 15, 533-550. doi: 10.1038/nrd.2016.29

Shepherd, N. E., Harrison, R. S., Ruiz-Gomez, G., Abbenante, G., Mason, J. M., and Fairlie, D. P. (2016). Downsizing the Bad Bh3 peptide to small constrained alpha-helices with improved ligand efficiency. Org. Biomol. Chem. 14, 10939-10945. doi: 10.1039/C6OB02185A

Shi, Y., Sang, P., Lu, J., Higbee, P., Chen, L., Yang, L., et al. (2020). Rational design of right-handed heterogeneous peptidomimetics as inhibitors of protein-protein interactions. J. Med. Chem. 63, 13187-13196. doi: 10.1021/acs.jmedchem.0c01638

Shi, Y., Teng, P., Sang, P., She, F., Wei, L., and Cai, J. (2016). Gammaaapeptides: design, structure, and applications. ACC Chem. Res. 49, 428-441. doi: 10.1021/acs.accounts.5b00492

Shin, W. H., Christoffer, C. W., and Kihara, D. (2017). In silico structure-based approaches to discover protein-protein interaction-targeting drugs. Methods 131, 22-32. doi: 10.1016/j.ymeth.2017.08.006

Sledz, P., and Caflisch, A. (2018). Protein structure-based drug design: from docking to molecular dynamics. Curr. Opin. Struct. Biol. 48, 93-102. doi: 10.1016/j.sbi.2017.10.010

Sohrabi, C., Foster, A., and Tavassoli, A. (2020). Methods for generating and screening libraries of genetically encoded cyclic peptides in drug discovery. Nat. Rev. Chem. 4, 90-101. doi: 10.1038/s41570-019-0159-2

Souers, A. J., Leverson, J. D., Boghaert, E. R., Ackler, S. L., Catron, N. D., Chen, J., et al. (2013). Abt-199, a potent and selective Bcl-2 inhibitor, achieves antitumor activity while sparing platelets. Nat. Med. 19, 202-208. doi: 10.1038/nm.3048

Stevenazzi, A., Marchini, M., Sandrone, G., Vergani, B., and Lattanzio, M. (2014). Amino acidic scaffolds bearing unnatural side chains: an old idea generates new and versatile tools for the life sciences. Bioorg. Med. Chem. Lett. 24, 5349-5356. doi: 10.1016/j.bmcl.2014.10.016

Tavakoli, F., and Ganjalikhany, M. R. (2019). Structure-based inhibitory peptide design targeting peptide-substrate binding site in Egfr tyrosine kinase. PLoS ONE 14:e0217031. doi: 10.1371/journal.pone.0217031

Teng, P., Niu, Z., She, F., Zhou, M., Sang, P., Gray, G. M., et al. (2018). Hydrogenbonding-driven $3 \mathrm{~d}$ supramolecular assembly of peptidomimetic zipper. J. Am. Chem. Soc. 140, 5661-5665. doi: 10.1021/jacs.7b11997

Teng, P., Shi, Y., Sang, P., and Cai, J. (2016). Gamma-aapeptides as a new class of peptidomimetics. Chemistry 22, 5458-5466. doi: 10.1002/chem.2015 04936

Teveroni, E., Luca, R., Pellegrino, M., Ciolli, G., Pontecorvi, A., and Moretti, F. (2016). Peptides and peptidomimetics in the P53/Mdm2/Mdm4 circuitry - a patent review. Expert Opin. Ther. Pat. 26, 1417-1429. doi: 10.1080/13543776.2017.1233179

Thanasomboon, R., Kalapanulak, S., Netrphan, S., and Saithong, T. (2020). Exploring dynamic protein-protein interactions in cassava through the integrative interactome network. Sci. Rep. 10:6510. doi: 10.1038/s41598-020-63536-0

Touti, F., Gates, Z. P., Bandyopadhyay, A., Lautrette, G., and Pentelute, B. L. (2019). In-solution enrichment identifies peptide inhibitors of protein-protein interactions. Nat. Chem. Biol. 15, 410-418. doi: 10.1038/s41589-019-0245-2

Touzeau, C., Maciag, P., Amiot, M., and Moreau, P. (2018). Targeting Bcl-2 for the treatment of multiple myeloma. Leukemia 32, 1899-1907. doi: 10.1038/s41375-018-0223-9

Tsai, C. J., Ma, B., and Nussinov, R. (2009). Protein-protein interaction networks: how can a hub protein bind so many different partners? Trends Biochem. Sci. 34, 594-600. doi: 10.1016/j.tibs.2009.07.007

Vagner, J., Qu, H., and Hruby, V. J. (2008). Peptidomimetics, a synthetic tool of drug discovery. Curr. Opin. Chem. Biol. 12, 292-296. doi: 10.1016/j.cbpa.2008.03.009

Vidal, M., Cusick, M. E., and Barabasi, A. L. (2011). Interactome networks and human disease. Cell 144, 986-998. doi: 10.1016/j.cell.2011.02.016

Wade, M., Li, Y. C., and Wahl, G. M. (2013). Mdm2, Mdmx and P53 in oncogenesis and cancer therapy. Nat. Rev. Cancer 13, 83-96. doi: 10.1038/nrc3430

Walensky, L. D., Kung, A. L., Escher, I., Malia, T. J., Barbuto, S., Wright, R. D., et al. (2004). Activation of apoptosis in vivo by a hydrocarbon-stapled Bh3 helix. Science 305, 1466-1470. doi: 10.1126/science.1099191

Wang, L., Zhang, L., Li, L., Jiang, J., Zheng, Z., Shang, J., et al. (2019). Small-molecule inhibitor targeting the Hsp90-Cdc37 protein-protein interaction in colorectal cancer. Sci. Adv. 5:eaax2277. doi: 10.1126/sciadv.aa $\mathrm{x} 2277$

Wang, Y., Ji, D., Lei, C., Chen, Y., Qiu, Y., Li, X., et al. (2021). Mechanistic insights into the effect of phosphorylation on ras conformational dynamics and its interactions with cell signaling proteins. Comput. Struct. Biotechnol. J. 19, 1184-1199. doi: 10.1016/j.csbj.2021.01.044

Wendt, M., Bellavita, R., Gerber, A., Efrem, N. L., van Ramshorst, T., Pearce, N. M., et al. (2021). Bicyclic beta-sheet mimetics that target the transcriptional coactivator beta-catenin and inhibit Wnt signaling. Angew. Chem. Int. Ed. Engl. doi: 10.1002/anie.202102082. [Epub ahead of print]

Winssinger, N., Damoiseaux, R., Tully, D. C., Geierstanger, B. H., Burdick, K., and Harris, J. L. (2004). Pna-encoded protease substrate microarrays. Chem. Biol. 11, 1351-1360. doi: 10.1016/j.chembiol.2004.07.015

Wlodawer, A. (2002). Rational approach to aids drug design through structural biology. Annu. Rev. Med. 53, 595-614. doi: 10.1146/annurev.med.53.052901.131947

Wojcik, P., and Berlicki, L. (2016). Peptide-based inhibitors of protein-protein interactions. Bioorg. Med. Chem. Lett. 26, 707-713. doi: 10.1016/j.bmcl.2015.12.084

Xiao, Y., and Konermann, L. (2015). Protein structural dynamics at the gas/water interface examined by hydrogen exchange mass spectrometry. Protein. Sci. 24, 1247-1256. doi: 10.1002/pro.2680

Yang, J., and Hu, L. (2019). Immunomodulators targeting the Pd-1/Pd-L1 proteinprotein interaction: from antibodies to small molecules. Med. Res. Rev. 39, 265-301. doi: 10.1002/med.21530

Yang, W., Sun, X., Zhang, C., and Lai, L. (2019). Discovery of novel helix binding sites at protein-protein interfaces. Comput. Struct. Biotechnol. J. 17, 1396-1403. doi: 10.1016/j.csbj.2019.11.001

Yang, X., Zhong, J., Zhang, Q., Qian, J., Song, K., Ruan, C., et al. (2018). Rational design and structure validation of a novel peptide inhibitor of the adenomatous-polyposis-coli (Apc)-rho-guanine-nucleotideexchange-factor-4 (Asef) interaction. J. Med. Chem. 61, 8017-8028. doi: 10.1021/acs.jmedchem.8b01112

Yao, Z., Aboualizadeh, F., Kroll, J., Akula, I., Snider, J., Lyakisheva, A., et al. (2020). Split intein-mediated protein ligation for detecting protein-protein interactions and their inhibition. Nat. Commun. 11:2440. doi: 10.1038/s41467-020-1 6299-1

Yin, H., and Hamilton, A. D. (2004). Terephthalamide derivatives as mimetics of the helical region of bak peptide target Bcl-Xl protein. Bioorg. Med. Chem. Lett. 14, 1375-1379. doi: 10.1016/j.bmcl.2003.09.096 
Zerbe, B. S., Hall, D. R., Vajda, S., Whitty, A., and Kozakov, D. (2012). Relationship between hot spot residues and ligand binding hot spots in protein-protein interfaces. J. Chem. Inf. Model. 52, 2236-2244. doi: 10.1021/ci300175u

Zhang, J., Hu, Y., Wu, N., and Wang, J. (2020). Discovery of influenza polymerase $\mathrm{Pa}-\mathrm{Pb} 1$ interaction inhibitors using an in vitro splitluciferase complementation-based assay. ACS Chem. Biol. 15, 74-82. doi: 10.1021 /acschembio.9b00552

Zhou, H., Zhou, W., Zhou, B., Liu, L., Chern, T. R., Chinnaswamy, K., et al. (2018). High-affinity peptidomimetic inhibitors of the Dcn1-Ubc12 protein-protein interaction. J. Med. Chem. 61, 1934-1950. doi: 10.1021/acs.jmedchem.7b01455
Conflict of Interest: The authors declare that the research was conducted in the absence of any commercial or financial relationships that could be construed as a potential conflict of interest.

Copyright $\odot 2021$ Wang, Ni, Liu and Lu. This is an open-access article distributed under the terms of the Creative Commons Attribution License (CC BY). The use, distribution or reproduction in other forums is permitted, provided the original author(s) and the copyright owner(s) are credited and that the original publication in this journal is cited, in accordance with accepted academic practice. No use, distribution or reproduction is permitted which does not comply with these terms. 